\title{
Structure and microstructure of the high pressure synthesised misfit layer compound $\left[\mathrm{Sr}_{2} \mathrm{O}_{2}\right]\left[\mathrm{CrO}_{2}\right]_{1.85}$
}

\author{
E. Castillo-Martínez ${ }^{\text {a }}$, A. Schönleber ${ }^{\text {b }}$, S. van Smaalen ${ }^{\text {b }}$, A.M. Arévalo-López ${ }^{\text {a }}$, M.A. Alario-Franco ${ }^{\text {a,* }}$ \\ a Departamento de Química Inorgánica, Laboratorio Complutense de Altas Presiones, Facultad de Química, Universidad Complutense de Madrid, Madrid 28040, Spain \\ ${ }^{\mathrm{b}}$ Laboratory of Crystallography, University of Bayreuth, Bayreuth 95440, Germany
}

\section{A R T I C L E I N F O}

\section{Article history:}

Received 29 December 2007

Received in revised form

13 March 2008

Accepted 22 March 2008

Available online 4 April 2008

Keywords:

Misfit layer

High pressure

Superspace

Single crystal

Chromium oxide

Inconmensurate modulated structure

\begin{abstract}
A B S T R A C T
The strontium chromium oxide $\left[\mathrm{Sr}_{2} \mathrm{O}_{2}\right]\left[\mathrm{CrO}_{2}\right]_{1.85}$ misfit layer compound has been synthesised at highpressure and high-temperature conditions. Electron diffraction patterns and high-resolution transmission electron microscopy images along [001] show the misfit character of the different layers composing the structure with a supercell along the incommensurate parameter $\mathbf{b} \approx 7 \mathbf{b}_{1} \approx 13 \mathbf{b}_{2}$. The modulated crystal structure has been refined within the superspace formalism against single-crystal X-ray diffraction data, employing the (3+1)-dimensional superspace group $C^{\prime} n m b\left(0 \sigma_{2} 0\right) 00$ s. The compound has a composite structure with lattice parameters $\mathbf{a}_{1}=5.182(1) \AA, \mathbf{b}_{1}=5.411(1) \AA, \mathbf{c}_{1}=18.194(3) \AA$ for the first, SrO, subsystem and the same a and $\mathbf{c}$, but with $\mathbf{b}_{2}=2.925(1) \AA$ for the second, $\mathrm{CrO}_{2}$, subsystem. The layer stacking is similar to that of orthorhombic $\mathrm{PbS}\left(\mathrm{TiS}_{2}\right)_{1.18}$, but with a much stronger intersubsytem bonding in the case of the oxide. The intersubsystem lattice mismatch is mainly handled by displacement modulations of the $\mathrm{Sr}$ atoms, correlated with modulations of the valence, the coordination and the anisotropic displacement parameters.
\end{abstract}

\section{Introduction}

In the last 10 years, a big effort has taken place in the synthesis and characterisation of a type of incommensurate oxide structures named as misfit layer compounds [1-3]. Besides their intrinsic importance as structurally unusual solids they have the added interest that many of them, in particular some mixed cobalt oxides, have been shown to have interesting thermoelectric properties, apparently related to their complex structures $[4,5]$.

Misfit layer structures were first studied in 1970's as structures which occurred in the mineral world, especially in many natural and synthetic chalcogenides [6]. This type of structure consists of the alternate stacking of two types of layers along the c-axis. The two types of layers have different chemical compositions, and distinct individual periodicities parallel to the layers. In one direction, e.g. the b direction, collinear lattice parameters may have an incommensurate length ratio, but perpendicular to this direction all compounds possess a common reciprocal lattice plane $\left(\mathbf{a}^{*}, \mathbf{c}^{*}\right)$. Compositions are typically given as $(M X)_{x}\left(T X_{2}\right)_{y}$ with $X=\mathrm{S}$, Se, O, $M=\mathrm{Sr}, \mathrm{Ca}, \mathrm{Bi}, \mathrm{Pb}, \mathrm{Ba}$, and $T=\mathrm{Nb}$, Ta, Ti, Co, Rh, Cr. In the $\mathrm{Nb}$ or Ta ternary rare-earth chalcogenides, the MX layer frequently is a two atoms thick rock salt layer oriented along [001], or another pseudoquadratic structure. It alternates with a

\footnotetext{
* Corresponding author. Fax: +34913944352.

E-mail address: maaf@quim.ucm.es (M.A. Alario-Franco).
}

variable number of hexagonal sandwiched layers of the $\mathrm{MoS}_{2}$ structure type-oriented along [001] —with the transition metal atom in a trigonal prismatic coordination [7,8]. On the other hand, only one hexagonal layer of the $\mathrm{CdI}_{2}$ type is found in sulphides when $M=\mathrm{Ti}, \mathrm{Cr}$, and $\mathrm{V}$. This atom then occupies the centre of a distorted octahedra [9]. This is also the case of all the misfit layer oxides known to date with $\mathrm{Co}$, Rh, or $\mathrm{Cr}[10,11]$. Moreover with the same layer stacking, it is frequent to find several polytypes of the same compound due to shifts of $\frac{1}{2}$ along the commensurate direction which fold the cell along $\mathbf{c}$, or to an alternate stacking of a monoclinic form with its mirror image, also doubling the c-parameter [12].

This type of structures has been studied by single-crystal X-ray diffraction [13] and by electron microscopy [14-16]. Due to the mutually incommensurate character of the two composing sublattices, apart from the reflections of each subsystem, satellite reflections appear in the diffraction pattern. An approximation by two independent lattices has often been used to describe these systems. A supercell approach, based on the closeness of the misfit parameter to a rational number has also been used. However, the most accurate method for structure refinement from diffraction data has been shown to be the higher dimensional superspace approach [13,17-19].

Here we present the modulated structure of a new misfit layer compound in the $\mathrm{Sr}-\mathrm{Cr}-\mathrm{O}$ system as it has been synthesised at high pressure (HP) and high temperature (HT). Evidence for its composite structure, as well as of the layer stacking has been 
obtained by electron diffraction and electron microscopy; the incommensurate composite structure has been determined from single-crystal X-ray diffraction data. The differences observed in the modulations with respect to misfit layer cobalt oxides are discussed.

\section{Experimental}

$\left[\mathrm{Sr}_{2} \mathrm{O}_{2}\right]\left[\mathrm{CrO}_{2}\right]_{1.85}$ has been prepared by intimately mixing powders of $\mathrm{SrO}$ (99.9\% Sigma Aldrich) and $\mathrm{CrO}_{2}$ (BASF) in the ratio 5.5:4.5, in a dry box to avoid $\mathrm{H}_{2} \mathrm{O}$ and $\mathrm{CO}_{2}$ absorption. The mixture was then pressed into gold capsules (up to $1100{ }^{\circ} \mathrm{C}$ ) or platinum capsules (over $1100^{\circ} \mathrm{C}$ ) for HP synthesis in a Belt-type press. Samples were first pressurised at a constant rate and then heated after $5 \mathrm{~min}$ of pressure stabilisation. After 30-210 min of reaction, the sample was quenched and then the pressure was released.

For transmission electron microscopy studies, samples were ground under liquid nitrogen, and subsequently dispersed in $n$ butanol with ultrasound. A drop of this suspension was evaporated on a copper grid coated with holey carbon. Selected area electron diffraction (SAED) was performed in a JEOL 2000FX electron microscope, having a double tilt $\pm 45^{\circ}$ sample holder; high-resolution transmission electron microscopy (HRTEM) was carried out in a JEOL 3000FEG electron microscope $\left(C_{\mathrm{s}}=0.6 \mathrm{~mm}\right)$. The cationic composition was analysed by X-ray energy dispersive spectroscopy in a Phillips CM200 TEM, with a Berilium sample holder, using $\mathrm{SrCrO}_{4}$ as standard for $k$ factors calibration. The experimental details for the electron energy loss spectroscopy (EELS) are reported elsewhere [33].

Several crystals of plate-like shape were glued on glass fibres for X-ray analysis. They were tested for crystal quality (shapes of diffraction spots) and checked for the lattice parameters from a multiphase reaction product (obtained at $4 \mathrm{GPa}, 1300^{\circ} \mathrm{C}, 210 \mathrm{~min}$ ) with a MAR 345 diffractometer with an image plate detector and

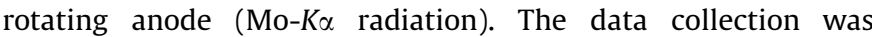
performed in two runs with 3 and $10 \mathrm{~min}$ of exposure per image, respectively. Data were reduced with the CrysAlis software [20], while the lattice parameters and the modulation wave vector were refined with NADA [21]. Absorption correction was performed for each dataset independently with JANA2000 [22]. Structural refinement was also carried out with JANA2000. Experimental details are given in Table 1.

\section{Results}

In order to obtain the $\mathrm{Sr}-\mathrm{Cr}$ misfit layer oxide, we had to avoid the stability field of the cubic $\mathrm{SrCrO}_{3}$ and the Ruddlesden Popper phase $\mathrm{Sr}_{3} \mathrm{Cr}_{2} \mathrm{O}_{7}$ [23]. The misfit layer compounds are obtained as the main phase in a wide range of pressures $(3,5-7 \mathrm{GPa})$ and temperatures $\left(900-1300^{\circ} \mathrm{C}\right)$ for reaction times longer than $30 \mathrm{~min}$ under the corresponding pressure and temperature conditions. Once quenched from HT and HP the compound is stable at ambient conditions for a long period of time (more than 1 year).

\subsection{Transmission electron microscopy}

The average cationic composition of the crystals analysed by EDS is $53.9(11) \% \mathrm{Sr}$ and $46.1(11) \% \mathrm{Cr}$. This was a key result for choosing the nominal composition in the synthesis. This leads to an approximate formula $\mathrm{Sr}_{2} \mathrm{Cr}_{1.8} \mathrm{O}_{\mathrm{y}}$ calculated for two $\mathrm{Sr}$ atoms per unit.

The typical electron diffraction pattern obtained along [0010] is shown in Fig. 1. It can be indexed on the basis of two lattices
Table 1

Crystal data and experimental conditions for the single-crystal X-ray diffraction

\begin{tabular}{|c|c|}
\hline \multicolumn{2}{|l|}{ Crystal data } \\
\hline Chemical formula & {$[\mathrm{SrO}]_{2}\left[\mathrm{CrO}_{2}\right]_{1.85}$} \\
\hline Chemical formula weight $(\mathrm{g} / \mathrm{mol})$ & 181.31 \\
\hline Dimensions $\left(\mathrm{mm}^{3}\right)$ & $0.0560 \times 0.0342 \times 0.0072$ \\
\hline Color & Green \\
\hline Cell setting & Orthorhombic \\
\hline Superspace group & $C^{\prime} n m b\left(0 \sigma_{2} 0\right) 00 s$ with $C^{\prime}=\left(\frac{11}{22} 0 \frac{1}{2}\right)$ \\
\hline Subsystem 1 & $\mathrm{SrO}$ \\
\hline$a(\AA)$ & $5.182(1)$ \\
\hline$b(\AA)$ & $5.411(1)$ \\
\hline$c(\AA)$ & $18.194(3)$ \\
\hline$V\left(\AA^{3}\right)$ & 510.2 \\
\hline Modulation wavevector & $(0,1.850(4), 0)$ \\
\hline$Z$ & 8 \\
\hline Subsystem 2 & $\mathrm{CrO}_{2}$ \\
\hline Superspace group & $C^{\prime} n m b\left(0 \sigma_{2}^{\prime} 0\right) 00 s$ \\
\hline$a(\AA)$ & $5.182(1)$ \\
\hline$b(\AA)$ & $2.925(1)$ \\
\hline$c(\AA)$ & $18.194(3)$ \\
\hline$V\left(\AA^{3}\right)$ & 275.8 \\
\hline Modulation wavevector & $(0,0.541(4), 0)$ \\
\hline$Z$ & 4 \\
\hline \multicolumn{2}{|l|}{ Experimental details } \\
\hline Temperature (K) & 293(2) \\
\hline Wavelenght $(\mathrm{Mo}-K \alpha)(\AA)$ & 0.71069 \\
\hline Phi range for data collection (deg) & 360 \\
\hline \multirow[t]{4}{*}{ Index ranges } & $-7 \leqslant H \leqslant 8$ \\
\hline & $-8 \leqslant K \leqslant 8$ \\
\hline & $-27 \leqslant L \leqslant 27$ \\
\hline & $-3 \leqslant M \leqslant 3$ \\
\hline Absorption correction & Gaussian integration $10 \times 10 \times 10$ \\
\hline$T_{\min }, T_{\max }(3 \mathrm{~min})$ & $0.4409,0.8380$ \\
\hline$T_{\min }, T_{\max }(10 \mathrm{~min})$ & $0.4525,0.8377$ \\
\hline No. of measured reflections & 79274,12161 \\
\hline No. of independent reflections (all/obs) & 2983,778 \\
\hline All & 2495,778 \\
\hline Main reflections & 712,473 \\
\hline Subsystem 1 & 430,271 \\
\hline Subsystem 2 & 200,136 \\
\hline Common & 82,66 \\
\hline Satellite reflections $(m=1)$ & 1070,248 \\
\hline Satellite reflections $(m=2)$ & 713,57 \\
\hline Criterion for observed reflections & $I>3 \sigma(I)$ \\
\hline$R_{\text {int }}$ (all, obs) \% & $18.67,7.60$ \\
\hline$R$ (all, obs) \% & $14.57,4.41$ \\
\hline wR (all, obs) \% & $6.07,5.43$ \\
\hline$S$ (all, obs) & $1.14,1.87$ \\
\hline No. of refined parameters & 56 \\
\hline Weighting scheme & $1 /\left[\operatorname{sig}(\mathrm{Fo})^{2}+(0.02 \mathrm{Fo})^{2}\right]$ \\
\hline Extinction correction & Isotropic type I \\
\hline Extinction coefficient & $0.17(4)$ \\
\hline
\end{tabular}

which are responsible of the two sets of main reflections and whose mutual modulation creates the set of satellite reflections. All reflections can be indexed by four indices $(\mathrm{hklm})$ on the basis of a set of $3+1$ vectors $\mathbf{M}^{*}=\left\{\mathbf{a}_{1}{ }^{*}, \mathbf{b}_{1}{ }^{*}, \mathbf{c}_{1}{ }^{*}, \mathbf{q}=\mathbf{b}_{2}{ }^{*}\right\}$, which reflects the common reciprocal lattice plane $\left(\mathbf{a}^{*}, \mathbf{c}^{*}\right)$ and the fact that main reflections of the second subsystem are satellite reflections of the first subsystem and the other way around. Therefore the first three vectors are independent and correspond to the reciprocal lattice of one subsystem and the fourth can be chosen as a linear combination of the first three; in this case we have chosen $\mathbf{q}=\mathbf{b}_{2}{ }^{*}$. Main reflections of the first and second subsystems have indices HKLO and HOLM respectively, whereas satellite reflections have indices $H K L M$ with both $K \neq 0$ and $M \neq 0$.

From electron diffraction approximate cell parameters can be derived as $\mathbf{a} \approx 5.3 \AA, \mathbf{b}_{1} \approx 5.4 \AA, \mathbf{b}_{2} \approx 2.9 \AA$, and $\mathbf{c} \approx 18.0 \AA$. 


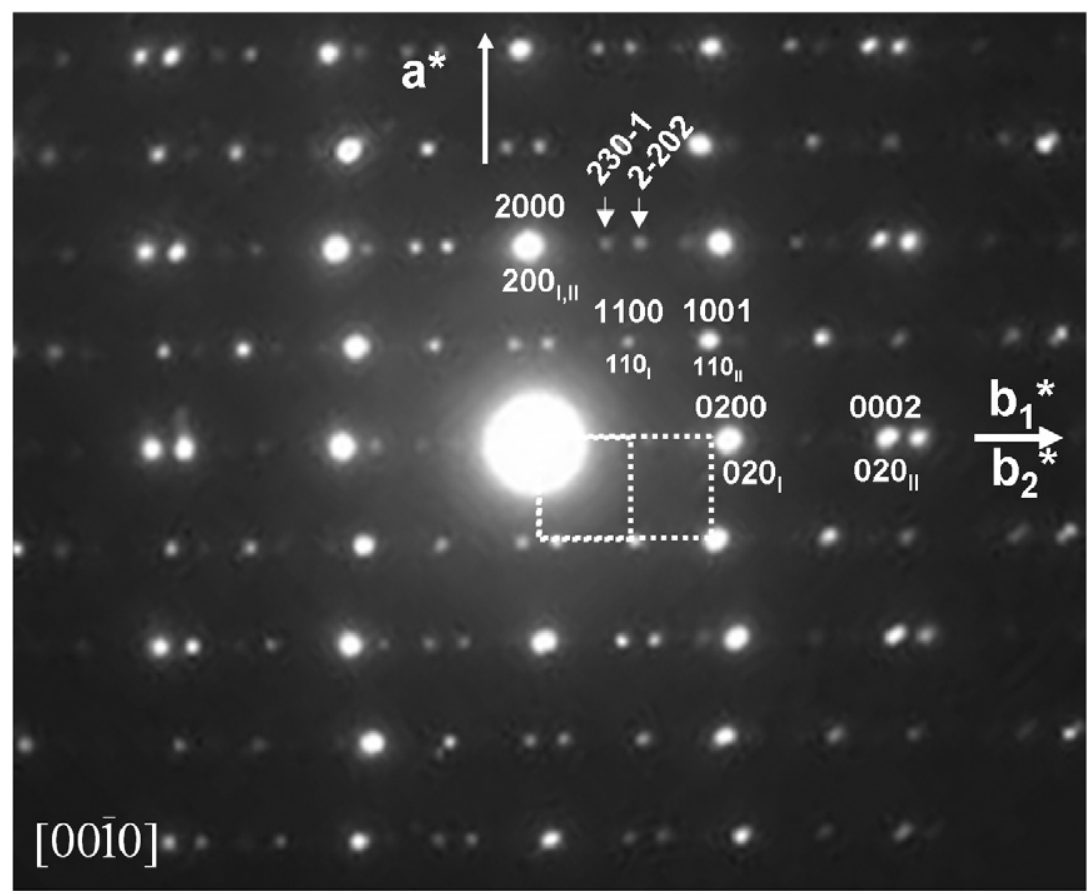

Fig. 1. [0010] electron diffraction pattern: three indices are used for describing the reciprocal space with reference to two different sublattices (drawn with dotted lines) with common $\mathbf{a}^{*}$-axes and parallel $\mathbf{b}_{1}{ }^{*}$ - and $\mathbf{b}_{2}{ }^{*}$-axes. Four indices are used in the superspace formalism.

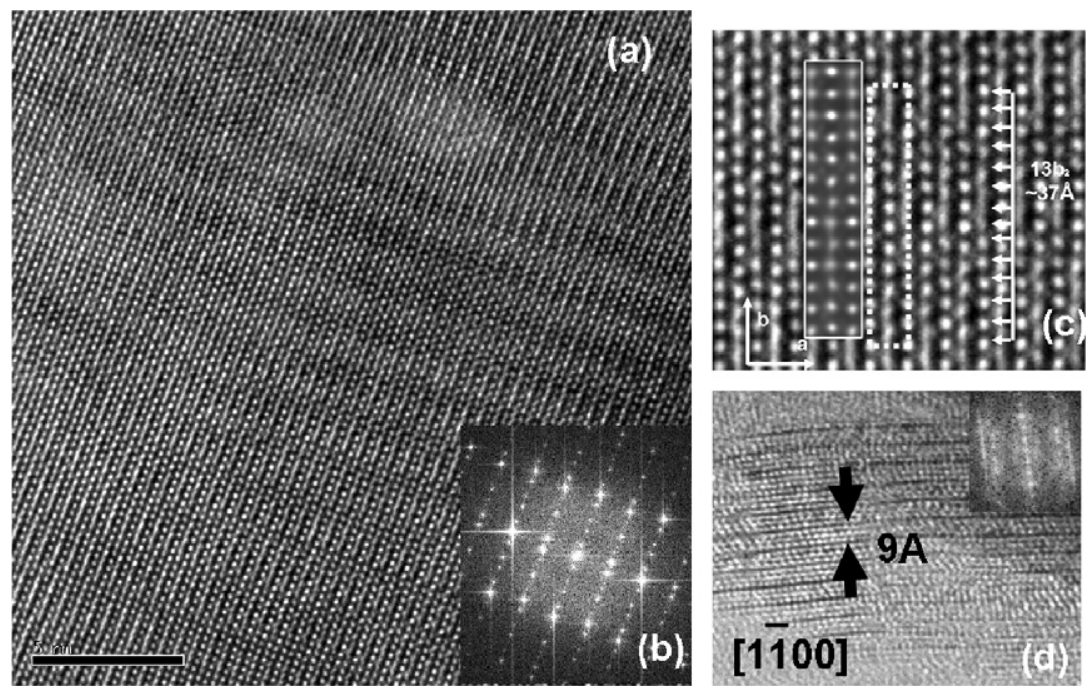

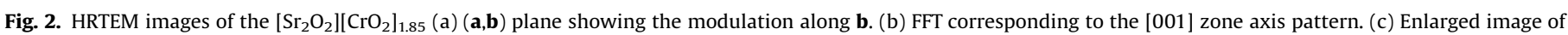
the $(\mathbf{a}, \mathbf{b})$ plane showing the supercell $\mathbf{b} \approx 7 \mathbf{b}_{1} \approx \mathbf{1 3}_{2}$. (d) Image showing the $\mathbf{c}$-axis.

HRTEM was used in order to identify the layer stacking and to confirm the modulated character of the structure (Fig. 2). Because of the high preferential orientation, the c-axis could only be imaged at folded edges. In all the images recorded perpendicular to the c-axis, the periodicity of the contrast repetition is $9 \AA$, as it can be seen in Fig. 2(d), which is the half of the $c$ lattice parameter. This HRTEM image reveals a $(2+1)$-layer cation arrangement, which is consistent with the intergrowth of a pseudohexagonal $\left[\mathrm{CrO}_{2}\right]_{\infty}$ layer and a pseudosquared rock salt layer $\left[\mathrm{Sr}_{x} \mathrm{Cr}_{y} \mathrm{O}_{z}\right]$. Within the $9 \AA$ layer, only a two atom thick $\left[\mathrm{SrO}_{2}\right]_{\infty}$ layer can be accommodated between the $\mathrm{CrO}_{2}$ layers, as in the related commensurate "misfit" layered cobaltite, $\left[\mathrm{Sr}_{2} \mathrm{O}_{2}\right]_{0.5}\left[\mathrm{CoO}_{2}\right]$ [24]. Moreover, this layer stacking gives a cationic ratio $\mathrm{Sr}: \mathrm{Cr}$ which depends on the misfit parameter $p=2 \times\left(b_{2} / b_{1}\right)=1.07$ consistent with the cationic ratio found by EDS 1.17(5). The in-plane parameters $5.2 \AA$ and $5.4 \AA$ are in agreement with those of rock salt type SrO, c.f. $a=5.160 \AA$ for the pure compound, and the $18 \AA$ c-axis found in electron diffraction is due to a typically found twinned orthorhombic polytype [12]. In the orthorhombic modification the monoclinic cell is alternately stacked with a unit cell of a mirror image of itself. The possibility of a five atoms thick rock salt layer [SrO-CrO-SrO-CrO-SrO] to explain this large $18 \AA$ cell has been left aside, on the one hand, because the composition is exactly the same in all crystals and, on the other hand, because we have not found any evidence of this layered stacking by HRTEM. Moreover the data collected from a single crystal happens to correspond to this $2 c$ polytype. 
Regarding the a,b plane, (Fig. 2a) in the high-resolution image of a very thin lamellar crystal it is possible to distinguish the modulation in intensities and sharpness along the b-axis (Fig. 2c). It is easy to observe a repetition distance of about $37 \AA$, which corresponds to a supercell of $7 b_{1} \approx 13 b_{2} \approx 37 \AA$. We have used the model obtained from the single-crystal diffraction data, without the oxygen atoms, to simulate the HRTEM image with the software EMS [25]. In Fig. 2(c), we have superposed a simulated image, for a defocus value of $-9 \mathrm{~nm}$ and a crystal thickness of $12.7 \mathrm{~nm}$. It shows good agreement with the experimental image. Here it is possible to observe the existence of the, almost commensurate, supercell of $37 \AA$ which corresponds to $13 \mathbf{b}_{1}$ and $7 \mathbf{b}_{2}$.

\subsection{Crystal structure refinement}

Unit cell dimensions and their standard deviations were determined from the measured X-ray diffraction data for each subsystem independently. For the first subsystem, $(v=1) \mathrm{SrO}$, the orthorhombic lattice parameters are $\mathbf{a}_{1}=5.182(1) \AA$, $\mathbf{b}_{1}=5.411(1) \AA, \mathbf{c}_{1}=18.194(3) \AA$, and for the second subsystem, $(v=2) \quad \mathrm{CrO}_{2}, \quad \mathbf{a}_{2}=5.182(1) \AA, \quad \mathbf{b}_{2}=2.925(1) \AA, \quad \mathbf{c}_{2}=18.191(3) \AA$. This confirms that both $\mathbf{a}_{v}{ }^{*}$ and $\mathbf{c}_{v}{ }^{*}$ are equal and therefore the reciprocal plane $\left(\mathbf{a}_{v}{ }^{*}, \mathbf{c}_{v}{ }^{*}\right)$ is common for the subsystems, as found in every misfit layer compound. The $\mathbf{b}_{v}$ are parallel with an incommensurate length ratio $b_{1} / b_{2}=\sigma_{2}$.

As explained for the description of the electron diffraction patterns, Bragg reflections are indexed with four indices ( $\mathrm{hklm}$ ) with respect to $\mathbf{M}^{*}=\left\{\mathbf{a}_{1}{ }^{*}, \mathbf{b}_{1}{ }^{*}, \mathbf{c}_{1}{ }^{*}, \mathbf{b}_{2}{ }^{*}\right\}$. With this choice of basis vectors, the general reflection condition $H+K+M=2 n$ is observed. This corresponds to a centring translation $\left(\frac{11}{22} 0 \frac{1}{2}\right)$, which belongs to a non-standard superspace centring, $C^{\prime}$. The other observed reflection conditions $H=2 n$ and $K+M=2 n$ for (HKOM) reflections imply the presence of glide planes $\left(m_{z}, 1 \mid \frac{1}{2} 000\right)$ and $\left(m_{z}, 1 \mid 0 \frac{1}{2} 0 \frac{1}{2}\right)$. And the reflection conditions $L+M=2 n$ and $K+L=2 n$ for (OKLM) reflections are due to $\left(m_{x}, 1 \mid \frac{1}{2} 0 \frac{11}{22}\right)$ and $\left(m_{x}, 1 \mid 0 \frac{11}{22} 0\right)$ glide planes. The resulting symmetry is given by the centrosymmetric orthorhombic superspace group $C^{\prime} n m b\left(0 \sigma_{2} 0\right) 00 s$ [26]. The symmetry operators are:

$\begin{array}{llll}x_{1}, & x_{2}, & x_{3}, & x_{4}, \\ -x_{1}, & \frac{1}{2}+x_{2}, & \frac{1}{2}+x_{3}, & x_{4}, \\ x_{1}, & \frac{1}{2}+x_{2}, & \frac{1}{2}+x_{3}, & \frac{1}{2}+x_{4}, \\ -x_{1}, & x_{2}, & -x_{3}, & \frac{1}{2}+x_{4}\end{array}$

The $W^{v}$ matrices that relate $\mathbf{M}^{*}$ with the reciprocal lattices and modulation vectors of the two individual subsystems, are chosen as the unit matrix for the first subsystem while for the second subsystem it is as

$W^{2}=\left(\begin{array}{llll}1 & 0 & 0 & 0 \\ 0 & 0 & 0 & 1 \\ 0 & 0 & 1 & 0 \\ 0 & 1 & 0 & 0\end{array}\right)$

The resulting subsystem superspace groups are $G_{\mathrm{s}}^{1}=G_{\mathrm{s}}^{2}=$ $C^{\prime} n m b\left(0 \sigma_{2} 0\right) 00 s$.

The initial structural model was obtained as the basic structure coordinates from the model of the orthorhombic polytype of $(\mathrm{PbS})_{1.18}\left(\mathrm{TiS}_{2}\right)[12]$ interchanging the $x$ and $y$ coordinates and with $z^{\prime}=-z$. Afterwards, they were shifted $\left(\frac{11}{44} 0 \frac{1}{4}\right)$ due to the change of origin of the same superspace group to $C^{\prime} n m b\left(0 \sigma_{2} 0\right) 00 s$. These basic coordinates and the isotropic atomic displacement parameters (ADPs, temperature factors) were refined using only the main reflections. Since the main reflections of one subsystem are the satellite reflections of the other subsystem, the main reflections still contain information about the modulations. Therefore it was possible to refine, next, the amplitudes of $\mathrm{Sr}$ and $\mathrm{Cr}$ for the displacive modulation against main reflections, and of $\mathrm{O} 1$ and $\mathrm{O} 2$ afterwards. Second harmonic displacive modulation functions were then refined for $\mathrm{Cr}, \mathrm{Sr}$ and for both oxygens. Subsequently, satellite reflections were included in the refinement. Up to second order satellite reflections were observed. Anisotropic ADPs (temperature factors) were then refined. Finally the refinement of up to second-harmonic modulation functions for the ADPs (temperature factors) of Sr clearly improved the quality of the refinement [27]. Refining the oxygen occupation did not improve the quality of the refinement.

The final model [28] gives a good fit for the main reflections of both subsystems as well as for first and second order satellite reflections (Table 2). The good fit to the data shows that $(\mathrm{SrO})_{2}\left(\mathrm{CrO}_{2}\right)_{1.85}$ is indeed isostructural to orthorhombic $(\mathrm{PbS})_{1.18} \mathrm{TiS}_{2}$ (Fig. 3) [12]. The atomic coordinates of the basic structure, along with the temperature parameters are listed in Table 3. The values of the harmonics of the modulations are listed in Table 4, and the calculated interatomic distances in Table 5.

\section{Discussion}

The projection of the structure of the composite crystal along a and $\mathbf{b}$ is shown in Fig. 3. The incommensurate character of the structure along the b-axis is clear in Fig. 3(a). Along the b-axis, a

Table 2

$R$ values and number of reflections for the best structure model of $\left[\mathrm{Sr}_{2} \mathrm{O}_{2}\right]\left[\mathrm{CrO}_{2}\right]_{1.85}$

\begin{tabular}{lcll}
\hline Reflection group & No. reflections & $R$ (obs) & wR (obs) \\
\hline All & 778 & 0.0441 & 0.0543 \\
Main reflections & 473 & 0.0422 & 0.0547 \\
Subsystem $\mathrm{SrO}$ & 271 & 0.0442 & 0.051 \\
Subsystem $\mathrm{CrO}_{2}$ & 136 & 0.0475 & 0.0671 \\
Common & 66 & 0.0298 & 0.0387 \\
Satellite reflections $(m=1)$ & 248 & 0.0438 & 0.0426 \\
Satellite reflections $(m=2)$ & 57 & 0.0878 & 0.0969 \\
\hline
\end{tabular}
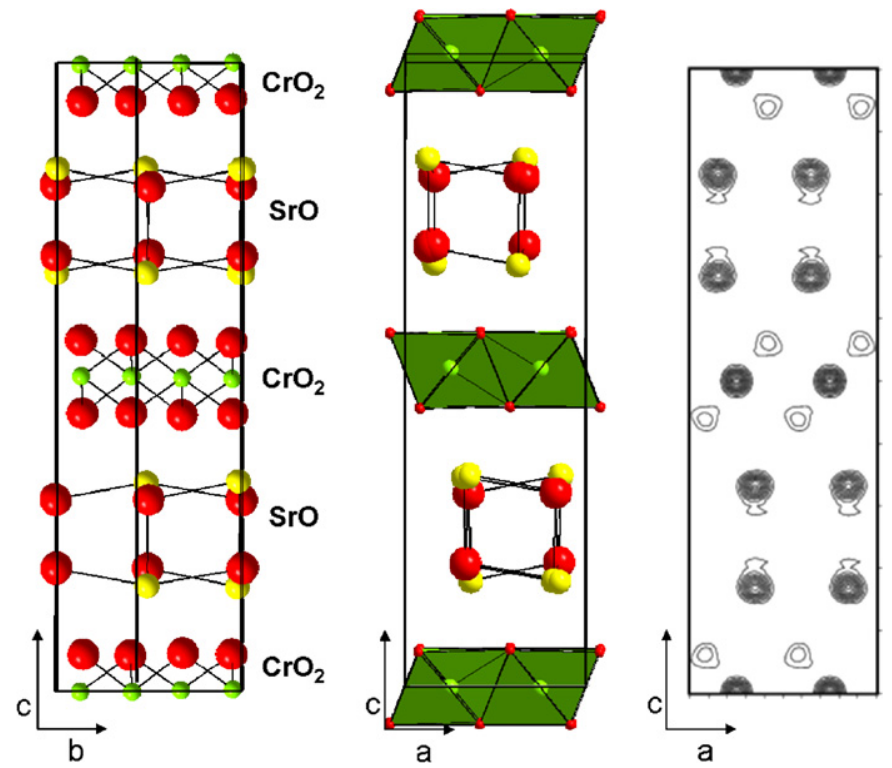

Fig. 3. Average structure of $\left[\mathrm{Sr}_{2} \mathrm{O}_{2}\right]\left[\mathrm{CrO}_{2}\right]_{1.85}$. (a) Projection along the common aaxis. (b) Projection along the incommensurate b-axis. Yellow and green circles stand for strontium and chromium atoms respectively, red circles for oxygen. (c) [010] projection of the Fourier map of the composite crystal summed up along the $x_{2}$ and $x_{4}$ coordinates. 
Table 3

Atomic positions in the basic structure and ADPs $\left(A^{2}\right)$ as obtained from the refinement of the modulated structure

\begin{tabular}{|c|c|c|c|c|c|c|c|c|}
\hline Atom & v & $x_{v}$ & $y_{0}$ & $z_{v}$ & U11 & U22 & U33 & U13 \\
\hline $\mathrm{Sr}$ & 1 & $0.3503(1)$ & 0 & $-0.3324(1)$ & $0.0120(3)$ & $0.0325(3)$ & $0.0107(2)$ & $0.0000(2)$ \\
\hline O1 & 1 & $0.3490(6)$ & 0.5 & $-0.3056(2)$ & $0.0061(7)$ & $0.0260(16)$ & $0.0161(15)$ & $-0.0013(12)$ \\
\hline $\mathrm{Cr}$ & 2 & 0.25 & 0.25 & 0 & $0.0031(3)$ & $0.0057(3)$ & $0.0079(3)$ & $-0.0006(2)$ \\
\hline $\mathrm{O} 2$ & 2 & $0.5815(4)$ & 0.25 & $-0.0583(1)$ & $0.0061(7)$ & $0.0093(9)$ & $0.0081(0)$ & $0.0008(8)$ \\
\hline
\end{tabular}

$\mathrm{U}^{12}=\mathrm{U}^{23}=0$ by symmetry for all atoms.

Table 4

Modulation parameters

\begin{tabular}{|c|c|c|c|c|c|c|c|}
\hline Atom $j$ & & $\mathrm{~A}_{n x}^{j}$ & $\mathrm{~A}_{n y}^{j}$ & $\mathrm{~A}_{n z}^{j}$ & $\mathrm{~B}_{n x}^{j}$ & $\mathrm{~B}_{n y}^{j}$ & $\mathrm{~B}_{n z}^{j}$ \\
\hline $\mathrm{Sr}$ & $\begin{array}{l}n=1 \\
n=2\end{array}$ & $\begin{array}{l}0.03060(11) \\
0\end{array}$ & $\begin{array}{l}0 \\
0.02050(16)\end{array}$ & $\begin{array}{l}-0.00149(7) \\
0\end{array}$ & $\begin{array}{l}0 \\
0.0020(3)\end{array}$ & $\begin{array}{l}0.0040(2) \\
0\end{array}$ & $\begin{array}{l}0 \\
-0.00003(9)\end{array}$ \\
\hline 01 & $\begin{array}{l}n=1 \\
n=2\end{array}$ & $\begin{array}{l}-0.0189(7) \\
0\end{array}$ & $\begin{array}{l}0 \\
0.0042(8)\end{array}$ & $\begin{array}{l}-0.0006(4) \\
0\end{array}$ & $\begin{array}{l}0 \\
-0.0019(19)\end{array}$ & $\begin{array}{l}0.0017(14) \\
0\end{array}$ & $\begin{array}{l}0 \\
0.0026(4)\end{array}$ \\
\hline $\mathrm{Cr}$ & $\begin{array}{l}n=1 \\
n=2\end{array}$ & $\begin{array}{l}0 \\
0\end{array}$ & $\begin{array}{l}0 \\
-0.0035(4)\end{array}$ & $\begin{array}{l}0 \\
0\end{array}$ & $\begin{array}{l}0.0028(2) \\
0\end{array}$ & $\begin{array}{l}0 \\
0\end{array}$ & $\begin{array}{l}-0.00254(6) \\
0\end{array}$ \\
\hline $\mathrm{O} 2$ & $\begin{array}{l}n=1 \\
n=2\end{array}$ & $\begin{array}{l}0 \\
0\end{array}$ & $\begin{array}{c}-0.0041(12) \\
0.009(1)\end{array}$ & $\begin{array}{l}0 \\
0\end{array}$ & $\begin{array}{r}0.0034(5) \\
-0.0010(7)\end{array}$ & $\begin{array}{l}0 \\
0\end{array}$ & $\begin{array}{r}-0.0015(2) \\
0.0016(2)\end{array}$ \\
\hline Sr1 & & $\mathrm{U}^{11} \cdot \sin / \cos$ & $\mathrm{U}^{22}$ & $\mathrm{U}^{33}$ & $\mathrm{U}^{12}$ & $\mathrm{U}^{13}$ & $\mathrm{U}^{23}$ \\
\hline $\begin{array}{l}\sin \\
\cos \end{array}$ & $n=1$ & $\begin{array}{l}0.0003(3) \\
0\end{array}$ & $\begin{array}{l}-0.0010(5) \\
0\end{array}$ & $\begin{array}{l}-0.0002(4) \\
0\end{array}$ & $\begin{array}{l}0 \\
0.0135(3)\end{array}$ & $\begin{array}{l}-0.0008(2) \\
0\end{array}$ & $\begin{array}{l}0 \\
-0.001(7)\end{array}$ \\
\hline $\begin{array}{l}\sin \\
\cos \end{array}$ & $n=2$ & $\begin{array}{l}0 \\
0.0108(5)\end{array}$ & $\begin{array}{l}0 \\
0.0276(5)\end{array}$ & $\begin{array}{l}0 \\
-0.00001(5)\end{array}$ & $\begin{array}{l}0.0009(5) \\
0\end{array}$ & $\begin{array}{l}0 \\
0.0005(6)\end{array}$ & $\begin{array}{l}-0.0013(4) \\
0\end{array}$ \\
\hline
\end{tabular}

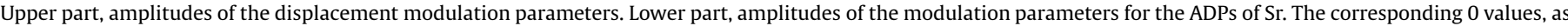
determined by symmetry.

commensurate composite is projected (Fig. 3b). It can be seen that it is composed of the alternate stacking along $\mathbf{c}$ of 1 layer of $\mathrm{CrO}_{2}$ and 2 layers of $\mathrm{SrO}$, with consecutive $\mathrm{CrO}_{2}$ layers related by a (001) mirror; this is responsible of the resulting orthorhombic symmetry. This type of orthorhombic stacking has been observed in sulphides [12] as well as in cobalt oxides and hydroxides $[29,30]$.

As it is seen in the Fourier map of Fig. 3(c), along the commensurate direction, a, the strontium atom is situated, between the two $\mathrm{O} 2$ atom rows and at the intersubsystem distance along c. Therefore, each $\mathrm{Sr}$ atom, have as nearest neighbours one apical $\mathrm{O} 1$ atom and four equatorial $\mathrm{O} 1$ atoms of the rock salt-type layer and two or three $\mathrm{O} 2$ atoms of the $\mathrm{CrO}_{2}$ layer, being the $\mathrm{Sr}$ atom coordinated either by seven or eight $\mathrm{O}$ atoms.

The $\mathrm{Cr}$ atom, in the middle of the $\mathrm{CrO}_{2}$ layer, is coordinated by six $\mathrm{O} 2$ atoms. It is the atom that is less perturbed by the modulation, with four shorter equatorial $\mathrm{Cr}-\mathrm{O} 2$ distances and 2 longer apical, all of them quite constant all along the crystal (Fig. 4a) (it only varies between $1.990(4)$ and $2.040(4) \AA$ ). Considering the three coordinated $\mathrm{O}$ ionic radius from Shannon tables [31], 1.36 $\AA$, this distance corresponds to a $\mathrm{Cr}$ ionic radius of $0.63-0.68 \AA$, which is larger than the expected for $\mathrm{Cr}^{4+}$ oxides in octahedral coordination. In fact the bond valence sum (BVS) [32] of the chromium atom gives an average valence of 3.48 , which is lower than the expected for the stoichiometric compound. Moreover it seems that $\mathrm{Sr}$ is not compensating for this charge imbalance, since its BVS values are quite close to 2 . See the discussion below.

We have performed a study by EEL spectroscopy on this and other $\mathrm{Cr}$ oxides. The $L_{3} / L_{2}$ ratio reflects the oxidation state for the
Table 5

Interatomic distances, atoms are labelled with respect to the atomic coordinates listed in Table 3

\begin{tabular}{|c|c|c|c|c|c|}
\hline & & $d_{\text {basic }}(\AA)$ & $d_{\text {average }}(\AA)$ & $d_{\min }(\AA)$ & $d_{\max }(\AA)$ \\
\hline $\mathrm{Sr}^{1}-\mathrm{O} 1^{1,2}$ & $2 x$ & $2.7489(6)$ & $2.755(7)$ & $2.658(9)$ & $2.862(3)$ \\
\hline $\mathrm{Sr}^{1}-\mathrm{O} 1^{3}$ & & $2.643(3)$ & $2.644(8)$ & $2.529(14)$ & $2.703(6)$ \\
\hline $\mathrm{Sr}^{1}-\mathrm{O} 1^{4}$ & & $2.630(3)$ & $2.631(8)$ & $2.589(7)$ & $2.718(14$ \\
\hline $\mathrm{Sr}^{1}-\mathrm{O} 1^{5}$ & & $2.512(4)$ & $2.513(8)$ & $2.477(8)$ & $2.561(15$ \\
\hline $\mathrm{Sr}^{1}-\mathrm{O} 2^{1}$ & & 2.3213 & & $2.452(4)$ & \\
\hline $\mathrm{Sr}^{1}-\mathrm{O}^{2}$ & & 2.3213 & & $2.431(4)$ & \\
\hline $\mathrm{Sr}^{1}-\mathrm{O}^{3}$ & & 2.4274 & & $2.480(4)$ & \\
\hline $\mathrm{Sr}^{1}-\mathrm{O}^{4}$ & & 2.4274 & & $2.516(4)$ & \\
\hline $\mathrm{Cr}^{1}-\mathrm{O} 2^{5,10}$ & $2 x$ & $2.019(2)$ & $2.019(4)$ & $1.992(7)$ & $2.040(4)$ \\
\hline $\mathrm{Cr}^{1}-\mathrm{O} 2^{6,7,8,9}$ & $4 x$ & $2.0068(15)$ & $2.007(4)$ & $1.990(4)$ & $2.033(4)$ \\
\hline $\mathrm{O} 2^{5}-02^{11,12}$ & $2 x$ & $2.925(4)$ & $2.925(5)$ & $2.888(5)$ & $2.944(4)$ \\
\hline $02^{5}-02^{6,7,13,14}$ & $4 x$ & $2.975(3)$ & $2.976(6)$ & $2.936(5)$ & $3.022(5)$ \\
\hline $\mathrm{O} 2^{5}-\mathrm{O}^{8,9}$ & $2 x$ & $2.712(3)$ & $2.713(5)$ & $2.676(5)$ & $2.771(5)$ \\
\hline $\mathrm{O} 2^{5}-\mathrm{O} 2^{15}$ & & $2.748(3)$ & $2.749(6)$ & $2.710(10)$ & $2.787(5)$ \\
\hline $\mathrm{O} 1^{1}-\mathrm{O} 2^{16}$ & & 2.7524 & & $2.810(7)$ & \\
\hline $\mathrm{O} 1^{1}-\mathrm{O} 2^{17}$ & & 2.7524 & & $2.687(17)$ & \\
\hline $\mathrm{O} 1^{1}-\mathrm{O} 2^{18}$ & & 2.8366 & & $2.822(16)$ & \\
\hline
\end{tabular}

$\mathrm{Sr}^{1}=\left(x_{1}, x_{2}, x_{3}, x_{4}\right), \mathrm{Cr}^{1}=\left(x_{1}, x_{2}, x_{3}, x_{4}\right), \mathrm{O}^{1}=\left(x_{1}, x_{2}, x_{3}, x_{4}\right), \mathrm{O} 1^{2}=\left(x_{1}, x_{2}-1, x_{3}, x_{4}\right)$, $\mathrm{O} 1^{3}=\left(x_{1}-\frac{1}{2}, x_{2}-\frac{1}{2}, x_{3}, x_{4}+\frac{1}{2}\right), \mathrm{O} 1^{4}=\left(x_{1}+\frac{1}{2}, x_{2}-\frac{1}{2}, x_{3}, x_{4}+\frac{1}{2}\right), O 1^{5}=\left(x_{1}, \frac{1}{2}-x_{2}, x_{3}\right.$, $\left.x_{4}\right), \mathrm{O}^{1}=\left(x_{1}, x_{2},-\frac{1}{2}-x_{3},-x_{4}\right), \mathrm{O}^{2}=\left(x_{1}, x_{2},-\frac{1}{2}-x_{3}, 1-x_{4}\right), \mathrm{O}^{3}=\left(x_{1}-\frac{1}{2}, \frac{1}{2}+x_{2}\right.$, $\left.-\frac{1}{2}-x_{3}, \frac{1}{2}-x_{4}\right), \quad \mathrm{O} 2^{4}=\left(x_{1}-\frac{1}{2}, \frac{1}{2}+x_{2},-\frac{1}{2}-x_{3}, \frac{3}{2}-x_{4}\right), \quad 2^{5}=\left(x_{1}, x_{2}, x_{3}, x_{4}\right)$, $\mathrm{O} 2^{6}=\left(x_{1}-\frac{1}{2}, \frac{1}{2}+x_{2}, x_{3}, x_{4}-\frac{1}{2}\right), \mathrm{O}^{7}=\left(x_{1}-\frac{1}{2}, \frac{1}{2}+x_{2}, x_{3}, x_{4}+\frac{1}{2}\right), \mathrm{O}^{8}=\left(1-x_{1}, x_{2}\right.$ $\left.-x_{3},-x_{4}\right), \quad \mathrm{O} 2^{9}=\left(1-x_{1}, x_{2},-x_{3}, 1-x_{4}\right), \quad 02^{10}=\left(\frac{1}{2}-x_{1}, \frac{1}{2}+x_{2},-x_{3}, \frac{1}{2}-x_{4}\right)$, $\mathrm{O} 2^{11}=\left(x_{1}, x_{2}, x_{3}, x_{4}-1\right), \mathrm{O} 2^{12}=\left(x_{1}, x_{2}, x_{3}, x_{4}+1\right), \mathrm{O} 2^{13}=\left(\frac{1}{2}+x_{1}, \frac{1}{2}+x_{2}, x_{3}, \frac{1}{2}+x_{4}\right)$, $\mathrm{O}^{14}=\left(\frac{1}{2}+x_{1}, \frac{1}{2}+x_{2}, x_{3}, \frac{1}{2}-x_{4}\right), \mathrm{O} 2^{15}=\left(\frac{3}{2}-x_{1}, \frac{1}{2}+x_{2},-x_{3}, \frac{1}{2}-x_{4}\right), \mathrm{O}^{16}=\left(x_{1}\right.$, $\left.\frac{1}{2}+x_{2},-\frac{1}{2}-x_{3}, \frac{1}{2}-x_{4}\right), \mathrm{O}^{17}=\left(x_{1}, \frac{1}{2}+x_{2},-\frac{1}{2}-x_{3}, \frac{3}{2}-x_{4}\right), \mathrm{O}^{18}=\left(\frac{1}{2}+x_{1}, \frac{1}{2}+x_{2}\right.$, $\left.-\frac{1}{2}-x_{3}, \frac{1}{2}-x_{4}\right)$. 
a

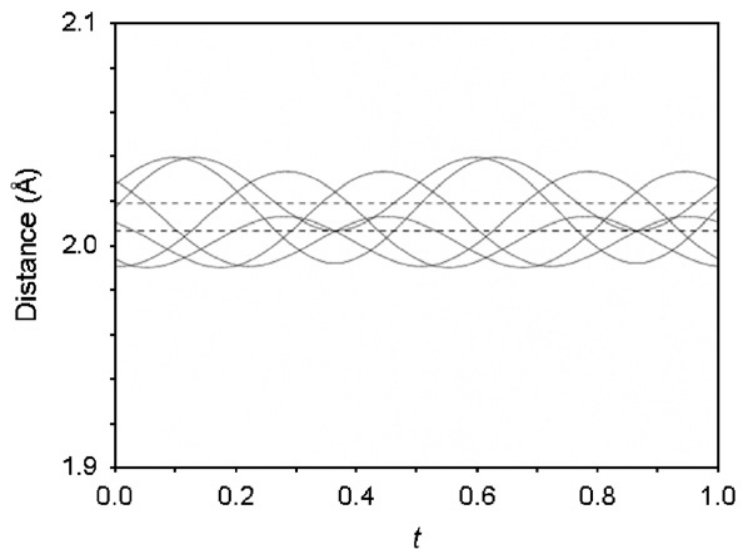

b

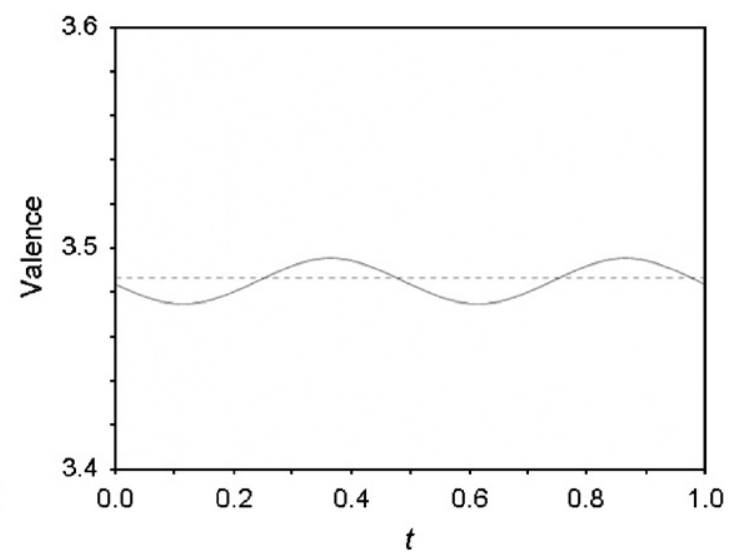

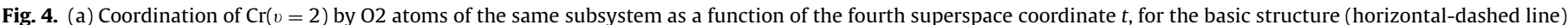
and for the modulated structure (solid line). (b) Bond valence sum of $\mathrm{Cr}$ as a function of $t$.

a

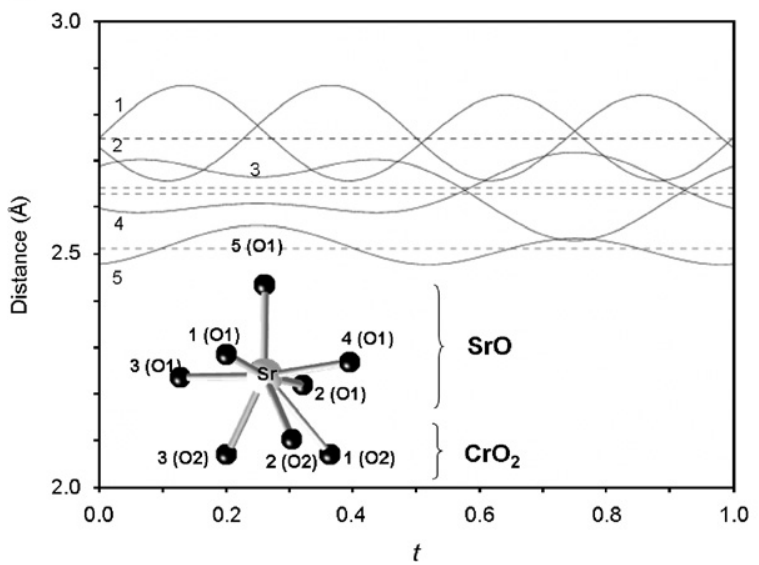

b

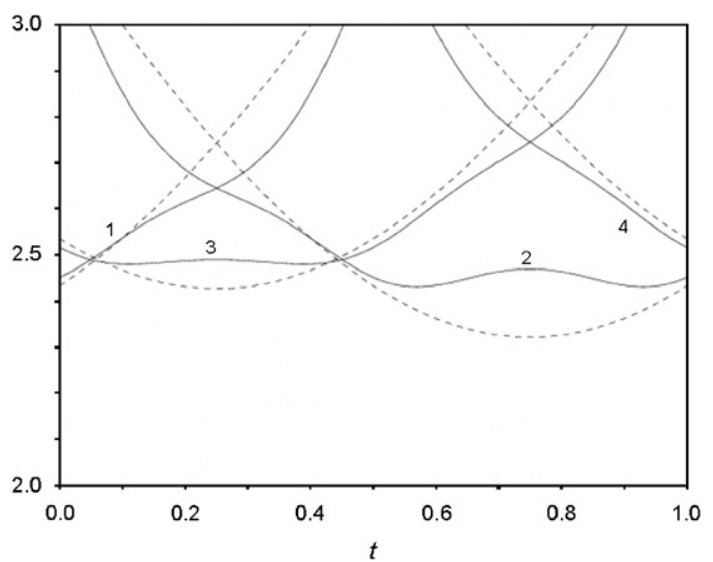

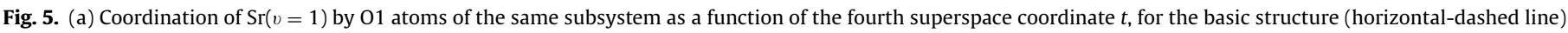

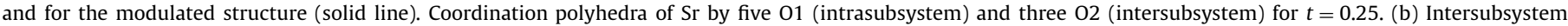

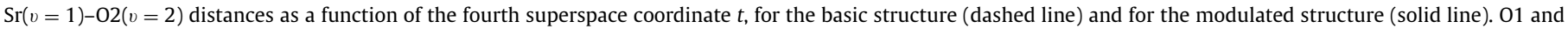
$\mathrm{O} 2$ are labelled as in Table 5.

transition metal [34-37]. We use $\mathrm{CrO}_{2}$ and $\mathrm{Cr}_{2} \mathrm{O}_{3}$ as standards for $\mathrm{Cr}^{4+}$ and $\mathrm{Cr}^{3+}$, respectively, and normalise their spectra to the height of the $\mathrm{Cr}-\mathrm{L}_{3}$ edge for direct comparison with $\left[\mathrm{SrO}_{2}\right.$ $\left[\mathrm{CrO}_{2}\right]_{1.8}$. In Fig. 7, it can be seen that the $L_{3} / L_{2}$ ratio of the misfit oxide is intermediate between that of $\mathrm{CrO}_{2}$ and $\mathrm{Cr}_{2} \mathrm{O}_{3}$. Making the integration of the peak intensities over a window of $5 \mathrm{eV}$ around the maxima of each edge, and taking their ratio, we obtain 1.37, 1.27, and 1.30 for $\mathrm{CrO}_{2}, \mathrm{Cr}_{2} \mathrm{O}_{3}$, and $\left[\mathrm{SrO}_{2}\left[\mathrm{CrO}_{2}\right]_{1.8}\right.$, respectively. This suggests that the $\mathrm{Cr}$ valence of the misfit is between $4+$ and $3+$, which agrees with the underbonded $\mathrm{Cr}$ result obtained by single-crystal X-ray refinement.

The larger values for the amplitudes of the positional (i.e., displacive) modulations are on both atoms of the rock salt layer, especially over the $\mathrm{Sr}$ atom, as it can be observed in Table 4, with the largest component along the common a direction. The resultant $\mathrm{Sr}-\mathrm{O} 1$ distances (Fig. 5a) have larger modulations than the $\mathrm{Cr}-\mathrm{O} 2$ distances. Comparing the intrasubsystem and intersubsytem $\mathrm{O}$ coordination by $\mathrm{Sr}$, it is observed that at least two, and sometimes three of the intersubsystem distances between $\operatorname{Sr}(v=1)$ and $02(v=2)$, plotted in Fig. 5(b), are amongst the five shorter intrasystem distances $\operatorname{Sr}(v=1)-01(v=1)$, being therefore possible to describe the $\mathrm{Sr}$ as seven or eight coordinated. The coordination polyhedra for $t=0.25$ is plotted in Fig. 5(a).
An interesting result is derived from the analysis of the interatomic distances. Fig. 5(b) shows the variation of the intersubsystem distance $\operatorname{Sr}(v=1)-02(v=2)$ along the fourth superspace coordinate for both, the basic structure and the structure considering the modulations. It is observed that the introduction of the modulation have two effects: One is that the shortest distance between subsystems is increased when the modulation is included, and at the same time the variation of this shortest distance along $t$ is smaller, showing the importance of the modulation for the intersystem stability. For the coordination of $\mathrm{Sr}$, the variation in the shortest distance is decreased from $0.170 \AA$ in the basic structure to $0.058 \AA$ in the modulated structure.

Additionally to the displacive modulations, the anisotropic ADPs (temperature factors) of $\mathrm{Sr}$ are largely affected by the different periodicity of the $\mathrm{CrO}_{2}$ subsystem. The ADPs of $\mathrm{Sr}$ as a function of $t$ are plotted in Fig. 6(a). The diagonal component along the c-axis is hardly modulated whereas the diagonal components along a and especially b suffer a large modulation. The equivalent isotropic ADP behaves the same way. It is noteworthy that the minimum, almost zero, values of $U_{11}, U_{22}$ and $U_{\text {eq }}$ happen for $t$ values of 0.25 and 0.75 . At this $t$ values the $\mathrm{Sr}$ atom is coordinated by eight oxygen atoms in the more symmetric coordination polyhedra with two pairs of equal distances and the 
a

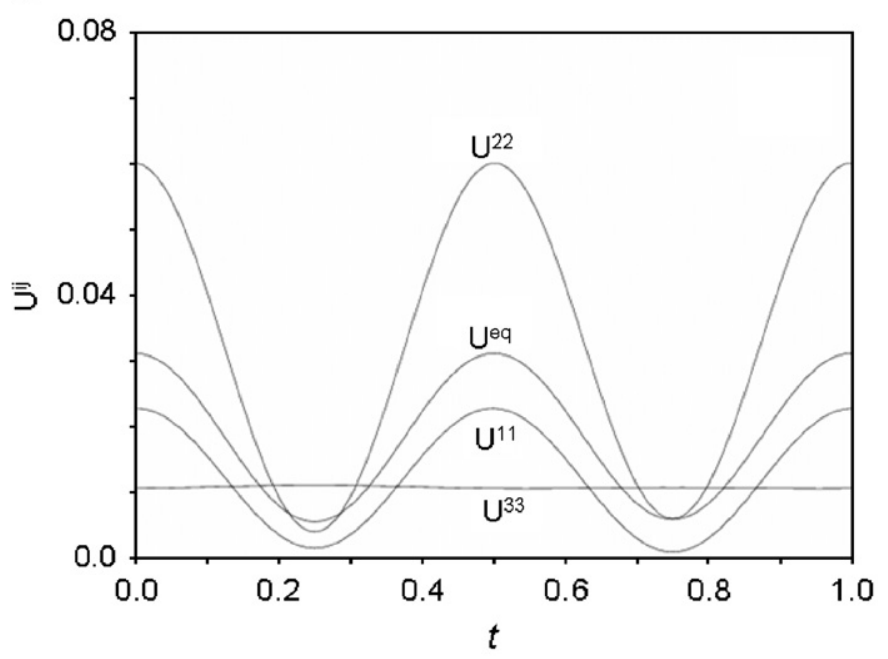

b

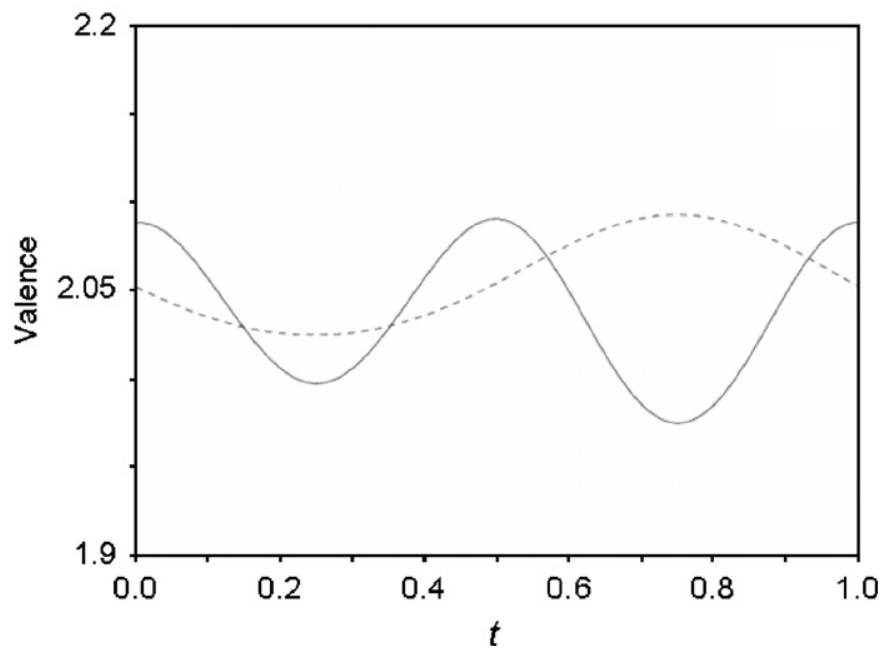

Fig. 6. (a) ADPs (temperature factors) of $\mathrm{Sr}$ as a function of $t . U_{\mathrm{eq}}$ is the averaged or equivalent to $U_{\text {iso. }}$ (b) Valence of $\mathrm{Sr}$ by $\mathrm{O}$ atoms of both subsystems.

smaller differences between distances. It also corresponds to relative minima in the value of BVSs (Fig. 6b). It is clear that a large correlation exists between the $\mathrm{Sr}-\mathrm{O}$ distances, the $\mathrm{Sr}$ ADP parameters, and the $\mathrm{Sr}$ valence, with large values of valence corresponding to short $\mathrm{Sr}-\mathrm{O}$ distances combined with large anisotropic displacements operating when the coordination is reduced. In this way the $\mathrm{O}$ atom of the $\mathrm{CrO}_{2}$ does not need to modulate significantly in order to adjust the misfit between both subsystems.

We have already mentioned that the bonding distances between $\operatorname{Sr}(v=1)$ and $02(v=2)$ are of comparable length as the intrasubsystem bond distances, and that the shortest $\mathrm{Sr}-\mathrm{O} 2$ distance is even shorter than the five $\mathrm{Sr}-\mathrm{O} 1$ bonds for every $t$ value. This reflects the strength of the intersubsystem interaction and the more ionic character of oxides versus sulphides which have a weaker interlayer interaction. This strong $\mathrm{M}(v=1)-\mathrm{O} 2(v=2)$ bond is also found in the $\mathrm{Sr}-\mathrm{Bi}$ cobaltite, where it is enhanced by the weak BiO-BiO intrasubsystem interaction within the four atoms thick rock salt-type layer [3]. Apart from this oxide, in other cobaltites, despite being shorter when compared to sulphides, the shortest intrasubsystem distance alternates from shorter to longer than the intrasubsystem interaction along $t[29,30,38,39]$. However, in this $\mathrm{Sr}-\mathrm{Cr}$ misfit oxide, both shortest distances become shorter for the same $t$

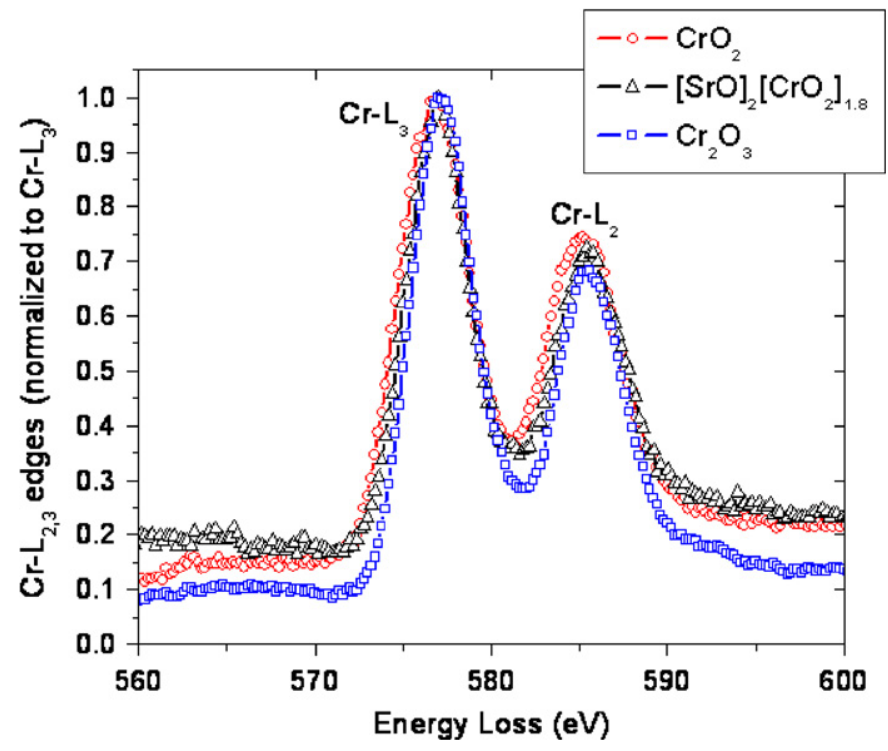

Fig. 7. EEL spectra in the region of the $\mathrm{Cr}$-edge of the misfit layer oxide $\left[\mathrm{Sr}_{2} \mathrm{O}_{2}\right]\left[\mathrm{CrO}_{2}\right]_{1.8}$ and two standard binary oxides, $\mathrm{CrO}_{2}$ and $\mathrm{Cr}_{2} \mathrm{O}_{3}$.

values, $t=0$ and 0.54 and longer for $t=0.25$ and 0.75 , as in $\left[\mathrm{Ca}_{0.85}(\mathrm{OH})\right]_{1.1564} \mathrm{CoO}_{2}[40]$.

Compared to misfit cobalt oxides, the $\mathrm{M}-\mathrm{O}$ distances in the $\mathrm{CrO}_{2}$ layer are less modulated, with $\mathrm{Cr}-\mathrm{O}$ distances modulated between $1.990(4)$ and $2.040(4) \AA$, but the type of octahedral distortion is the same with average O2-O2 distances of $2 \times 2.925(4)$ and $4 \times 2.976(5) \AA$ for the $\mathrm{O} 2$ in the same layer and $2 \times 2.713(5)$, and $1 \times 2.748(5) \AA$ for the three $02-02$ shared edges distances, forming a compressed $\left[\mathrm{CrO}_{2}\right]$ layer along [001] that avoids too short $\mathrm{Cr}-\mathrm{Cr}$ distances.

Regarding the modulation in the distances of the RS-type layer of the $\mathrm{Sr}-\mathrm{Cr}$ misfit, the largest difference between the maxima and minimum $\mathrm{Sr}-\mathrm{O} 1$ distance for the same bond is that observed for $01^{1}$ and $01^{2}$, with a difference of $0.204 \AA$. This value is slightly larger than that observed in the orthorhombic form of $\left[\mathrm{Ca}_{2} \mathrm{CoO}_{3}\right]\left[\mathrm{CoO}_{2}\right]_{1.62}, \sim 0.13 \AA$ [29], the Bi-substituted compound $\sim 0.15 \AA$ [38], or the Sr-Bi-based cobaltite $\sim 0.07 \AA$ [3]. However, this difference becomes much larger for the $\mathrm{Cu}$-substituted calcium cobaltite $\sim 0.5 \AA$ [39] and even more in the case of the "isomorphous" $[2 \mathrm{Ca}(\mathrm{OH})]_{0.576} \mathrm{CoO}_{2}$, and the monoclinic $\left[\mathrm{Ca}_{0.85}(\mathrm{OH})\right]_{1.1564} \mathrm{CoO}_{2}$, both synthesised at $\mathrm{HP}-\mathrm{HT}, \sim 1.1 \AA$ $[30,40]$. These hydroxides present very short $\mathrm{Ca}-\mathrm{OH}$ distances, with very large in-plane deformations in the $\mathrm{CaOH}$ layers, which are attributed to the HP employed in the synthesis. However, we believe that the presence of $\mathrm{H}$, whose actual position is unknown, might be the responsible of this large distortion since we are not observing such deformations in this HP misfit layer oxide. Moreover, the lack of this large distortion in the present $\mathrm{Sr}-\mathrm{Cr}$ misfit layer leads us to rule out a possible hydroxide for oxide substitution to explain the low valence found in $\mathrm{Cr}$. On the other hand, as we mix the reactants and fill the cell in a dry box, the presence of hydroxide is quite unexpected.

Amongst the known $\mathrm{Sr}-\mathrm{Cr}$ oxides synthesised at HP this is the first reported compound non-related to the perovskite structure. In the cubic perovskite and Ruddlesden Popper phases the average $\mathrm{Cr}-\mathrm{O}$ distances, corresponding to $\mathrm{Cr}^{4+}$, are shorter, but they are increasingly larger for the compounds with a smaller number of perovskite blocks between the rock salt layer type, $\mathrm{SrO}$ (i.e. $d_{\langle\mathrm{Cr}-\mathrm{O}\rangle}=1.909 \AA$ in $\mathrm{SrCrO}_{3}, 1.917 \AA$ in $\mathrm{Sr}_{3} \mathrm{Cr}_{2} \mathrm{O}_{7}$, and $1.968 \AA$ for $\mathrm{Sr}_{2} \mathrm{CrO}_{4}$ synthesised at ambient pressure) $[23,41]$. It seems that the structure is playing a role in the mean distance for the same oxidation state. In the present compound, the average $\mathrm{Cr}-\mathrm{O}$ 
distance is $2.011 \AA$, which is larger than the distance found in any of the perovskite and related phases; however, it is considerably shorter than that found in the closely related compound $\mathrm{SrCr}_{2} \mathrm{O}_{4}$ [42]. Its structure is composed of similar $\mathrm{CrO}_{2}$ layers, of the $\mathrm{CdI}_{2}$ type, with a layer of $\mathrm{Sr}$ atoms between the $\mathrm{CrO}_{2}$ layers, and the average distances $\mathrm{Cr}-\mathrm{O}$ are 2.04 and $2.05 \AA$. For the $\mathrm{Sr}-\mathrm{Cr}$ misfit oxide, as for $\mathrm{SrCr}_{2} \mathrm{O}_{4}$ the $\mathrm{Cr}-\mathrm{O}$ distances are larger than those reported for $\mathrm{Cr}^{4+}$ and $\mathrm{Cr}^{3+}$, respectively. This indicates a similar trend in this type $\mathrm{CrO}_{2}$ layered compounds. The short $\mathrm{O} 2-\mathrm{O} 2$ bonds which form the shared edge of $\mathrm{CrO}_{6}$ octaedra, along with the not too long $01-02$ intersubsystem bond could explain this reduced valence in the $\mathrm{Cr}$. However, the possibility of oxygen nonstoichiometry can not be discarded, this is usually found in misfit-layer cobalt oxides [43].

\section{Conclusions}

We have obtained a misfit layer oxide $\left(\mathrm{Sr}_{2} \mathrm{O}_{2}\right)\left(\mathrm{CrO}_{2}\right)_{1.85}$ by working at HP and HT conditions. This proves the ability of HP to yield oxides with misfit layer structures as well as it widens the range of cations which can form such type of structures. The incommensurately modulated structure has been successfully solved by means of single-crystal X-ray diffraction with the superspace group $C^{\prime} n m b\left(0 \sigma_{2} 0\right) 00 s$. This orthorhombic structure corresponds to the stacking of two $\mathrm{SrO}$ and one $\mathrm{CrO}_{2}$ layer, as initially shown by HRTEM, and their mirror. The atoms of the $\mathrm{Sr}-\mathrm{O}$ layer present the larger displacement modulations, specially the $\mathrm{Sr}$ atoms have the largest displacements, correlated with large modulations in the thermal parameters so as to accommodate the structural mismatch. The intersubsystem bond is particularly strong, in the whole system, which results in an underbonded $\mathrm{Cr}$ atom with an estimated valence of 3.48 .

\section{Acknowledgments}

We thank Dr. Antonio Dos santos and Dr. Rafael Tamazyan for helpful discussions. Financial support was funded from CICYT, Project MAT2004-01641, Comunidad Autonoma de Madrid, Programa MATERYENER, PRICYT S-0505/PPQ-0093 (2006) and Fundación Areces. ECM acknowledges UCM for a Ph.D. Grant. We also thank the "Luis Bru" Electron Microscopy Center.

\section{References}

[1] P. Boullay, B. Domenges, M. Hervieu, D. Groult, B. Raveau, Chem. Mater. 8 (1996) 1482.

[2] P. Boullay, R. Seshadri, F. Studer, M. Hervieu, D. Groult, B. Raveau, Chem. Mater. 10 (1998) 92.
[3] H. Leligny, D. Grebille, O. Pérez, A.C. Masset, M. Hervieu, B. Raveau, Acta Crystallogr. B 56 (1999) 173.

[4] Y. Miyazaki, K. Kudo, M. Akoshima, Y. Ono, Y. Koyke, T. Kajitani, Jpn. J. Appl. Phys. 39 (2000) L531.

[5] A. Maignan, L.B. Wang, S. Hérbert, D. Pelloquin, B. Raveau, Chem. Mater. 14 (2002) 1231.

[6] E. Mackovivky, B.G. Hyde, Struct. Bonding 46 (1981) 99.

[7] S. van Smaalen, J. Phys.: Condens. Matter 1 (1989) 2791.

[8] A. Meerschaut, L. Guémas, C. Auriel, J. Rouxel, Eur. J. Solid State Inorg. Chem. 27 (1990) 557.

[9] G.A. Wiegers, A. Meetsma, S. van Smaalen, R.J. Haange, J.L. De Boer, Solid State Commun. 75 (1990) 689.

[10] K. Yubuta, S. Okada, Y. Miyazaki, I. Terasaki, T. Kajitani, Jpn. J. Appl. Phys. 44 (2005) 8557.

[11] M. Hervieu, Ph. Boullay, C. Michel, A. Maignan, B. Raveau, J. Solid State Chem. 142 (1999) 305.

[12] S. van Smaalen, J.L. De Boer, Phys. Rev. B 46 (1992) 5.

[13] K. Kato, Acta Crystallogr. B 46 (1990) 39.

[14] L.C. Otero-Diaz, J.D. Fitzgerald, T.B. Williams, B.G. Hyde, Acta Crystallogr. B 41 (1985) 405.

[15] S. Kuypers, J. Van Landuyt, S. Amelinckx, J. Solid State Chem. 86 (1990) 212.

[16] L.N. Salamanca-Oviedo, A. Gómez-Herrero, A.R. Landa-Cánovas, L.C. OteroDíaz, Micron 31 (2000) 597.

[17] A. Janner, T. Janssen, Acta Crystallogr. A 36 (1980) 408.

[18] S. van Smaalen, Phys Rev. B 43 (1991) 11330.

[19] S. van Smaalen, Incommensurate Crystallography, Oxford University Press, 2007.

[20] Oxford Diffraction, Oxford Diffraction, Ltd., Xcalibur CCD system, CrysAlis Software system, Version 1.171.32, 2007.

[21] A. Schönleber, M. Meyer, G. Chapuis, J. Appl. Crystallogr. 34 (2001) 777.

[22] V. Petricek, M. Dusek, L. Palatinus, The Crystallographic Computing System, Institute of Physics, Praha, Czech Republic, 2000.

[23] E. Castillo-Martínez, M.A. Alario-Franco, Solid State Sci. 9 (2007) 551.

[24] T. Nagai, K. Sakai, M. Karppinen, T. Asaka, K. Kimono, A. Yamazaki, H. Yamauchi, Y. Matsui, J. Solid State Chem. 179 (2006) 1898.

[25] P.A. Stadelmann, Ultramicroscopy 21 (1987) 131.

[26] P.M. DeWolff, T. Janssen, A. Janner, Acta Crystallogr. A 37 (1981) 625.

[27] A. Jobst, S. van Smaalen, Acta Crystallogr. B 58 (2002) 179.

[28] Crystallographic data (excluding structure factors) for the structure reported in this paper have been deposited with Incommensurate Crystal Structure Database in the Bilbao Crystallographic Server as supplementary publication no. comp1210156195.

[29] S. Lambert, H. Leligny, D. Grebille, J. Solid State Chem. 160 (2001) 322.

[30] M. Isobe, M. Onoda, M. Shizuya, M. Tanaka, E. Takayama-Muromachi, J. Phys. Soc. Japan 76 (2007) 014602

[31] R.D. Shannon, Acta Crystallogr. A. 32 (1976) 751.

[32] N.E. Brese, M. O'Keffe, Acta Crystallogr. B 47 (1991) 192.

[33] A.M. Arévalo-López, E. Castillo-Martínez, M.A. Alario-Franco, to be published.

[34] D.H. Pearson, C.C. Ahn, B. Fultz, Phys. Rev. B 47 (1993) 8471.

[35] C. Mitterbauer, G. Kothleitner, W. Grogger, H. Zandbergen, B. Freitag, P. Tiemeijer, F. Hofer, Ultramicroscopy 96 (2003) 469.

[36] E. Stoyanov, F. Langenhorst, G. Steinle-Neumann, Am. Miner. 92 (2007) 577.

[37] T.L. Daulton, B.J. Little, Ultamicroscopy 106 (2006) 561.

[38] Y. Miyazaki, Y. Suzuki, M. Onoda, Y. Ishii, Y. Morii, T. Kajitani, Jpn. J. Appl. Phys. 43 (2004) 6252.

[39] Y. Miyazaki, Y. Suzuki, M. Onoda, Y. Ishii, Y. Morii, T. Kajitani, Jpn. J. Appl. Phys. 42 (2003) 7467.

[40] M. Isobe, M. Onoda, M. Shizuya, M. Tanaka, E. Takayama-Muromachi, J. Am. Chem. Soc. 129 (2007) 14585.

[41] T. Baikie, Z. Ahmad, M. Srinivasan, A. Maignan, S.S. Pramana, T.J. White, J. Solid State Chem. 180 (2007) 1538.

[42] H. Pausch, Hk. Müller-Buschbaum, Z. Anorg. Allg. Chem. 405 (1974) 1.

[43] Y. Morita, J. Poulsen, K. Sakai, T. Motohashi, T. Fujii, I. Terasaki, H. Yamauchi, M. Karppinen, J. Solid State Chem. 177 (2004) 3149. 